\title{
RESENHAS
}

\section{Interterritorialidade. Mídias, Contextos e Educação.}

por Mariana Oliveira

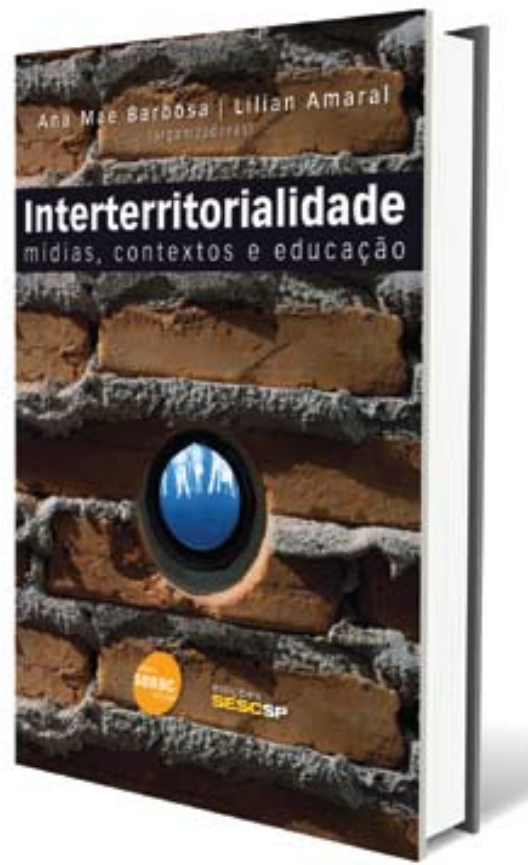

Título: Interterritorialidade Mídias, Contextos e Educação

Organizadoras: Ana Mae Barbosa e Lilian Amaral

Editora: Edições Sesc SP
Há alguns anos tínhamos categorias estanques para uma arte, que buscava sua pureza, territórios bem definidos por fronteiras fortes, intransponíveis, e meios de comunicação também mais estáveis, gerenciados por um pequeno grupo de privilegiados. Hoje, ao contrário, temos uma arte cada vez mais "impura", mais híbrida, que adentra por caminhos nunca antes imaginados, fronteiras porosas e territórios "inter" culturais, meios de comunicação dinâmicos com livre acesso. As certezas foram substituídas pelas dúvidas, o puro pelo híbrido.

Foi dentro desse contexto que o Sesc São Paulo iniciou, em 2005, o projeto Interterritorialidade: fronteiras intermídias, contextos e educação, promovendo vários módulos de debates, workshops e mesas redondas que se propunham a discutir os caminhos da arte no mundo contemporâneo. Agora, as experiências e os resultados dessas discussões chegam às mãos do público no livro Interterritorialidade - mídias, contextos e educação, organizado por Ana Mae Barbosa e Lilian Amaral. Os artigos selecionados trazem as experiências variadas de alguns participantes do evento nesse novo contexto, no qual as linguagens artísticas se inter-relacionam - formando obras cada vez mais híbridas - expandem-se para além das fronteiras e estabelecem uma relação particular com os meios de comunicação de massa. Através dos relatos dos diversos autores, cada um desde sua área de conhecimento nas ciências humanas (psicanalistas, antropólogos, arteeducadores, artistas plásticos, bailarinos, produtores de TV...), vamos percebendo as formas de produção e de recepção da arte atualmente e fica claro o papel determinante da mediação e da educação no processo de apropriação desses bens culturais híbridos.

Mas qual o lugar da arte no mundo contemporâneo? Ou como pergunta Ana Mae Barbosa, um dos maiores nomes da arte-educação mundial, na apresentação do livro: "Que lugares, num mundo marcado pelo nomadismo, impermanência e simultaneidade, as manifestações artísticas podem ocupar?" Os relatos dos autores mostram que esse lugar não está parado, não está apenas nos museus e nas instituições artísticas. A arte foi lançada na arena social. A arte está na rua, na internet, em hospitais, na TV.

Durante anos, a história da arte foi organizada em uma linha evolutiva, como uma sucessão de correntes que iam substituindo umas as outras, sem qualquer inter-relação. O crítico Clement Greemberg, por exemplo, acreditava que a pintura moderna era a grande expressão dessa constante evolução artística. Com sua pureza e autonomia, a arte haveria chegado ao seu ápice. Para manter-se pura, a arte moderna protegeu as fronteiras de seus territórios com todas suas 
forças, mas a dinâmica do mundo contemporâneo impediu a manutenção desse isolamento.

Andreas Huyssen utiliza o termo Grande Divisão para caracterizar a intransponível barreira que existia entre a cultura de massa e a cultura erudita. Foi esse vácuo que separou por muito tempo arte moderna da cultura de massa, isolando-a em seu próprio território de fronteiras fechadas. Para Huyssen, a cultura contemporânea vive o momento pós Grande Divisão, um momento em que as relações entre as linguagens artísticas e a mídia tornam-se espaços de troca, de apropriações. É justamente nesse interterritório, nesse espaço intermediário, que a arte vem transitando de forma livre. Os territórios, que segundo o geógrafo Milton Santos são espaços de intensa relação de poder institucionalizados, estão sendo relativizados. A arte não está apenas dentro do museu, das galerias, das instituições, ela ocupou lugares, mídias, espaços antes desvinculados de qualquer produção artística.

Diante de tantas mudanças, a relação com o público também passa por um processo de reorganização. O artigo inicial, assinado por Ana Mae Barbosa, trata a questão da interterritorialidade no campo da arte-educação. Sua primeira constatação é que a grande maioria dos arte-educadores sentem-se desconfortáveis com a arte "inter" dos dias atuais, já que muitos deles foram educados dentro dos princípios do alto modernismo, com sua forte defesa das especificidades artísticas. Se os professores ainda não se sentem a vontade com a pluralidade da arte contemporânea, jamais poderão conduzir a mediação com seus alunos de forma realmente efetiva. Para ela, a formação desses profissionais com currículos engessados nas especialidades não ajuda em nada no avanço da absorção das novas possibilidades que envolvem o fazer artístico.

Ana Mae volta-se à ideia da obra de arte total para aproveitar o conceito de integração das artes. A partir do relato de seus exemplos conclui que no passado essa pretensa integração possuía um regente, que concentrava em si todo o poder: "O rompimento das barreiras territoriais, hoje, operado principalmente pelas tecnologias contemporâneas dispensa o regente. O poder integrador está no grupo, no caso dos coletivos, e muitas vezes concentrado no artista sozinho, que se apropria da música manipula o espaço e dá conta da materialidade do seu simulacro". Antes, segundo a autora, tínhamos uma integração concêntrica, hoje temos uma alocêntrica. 
Na sequencia, a outra organizadora, a artista audiovisual Lilian Amaral, faz um relato inspirado na sua experiência dentro da Rede Nacional de Artes Visuais da Funarte. Um dos projetos, Interterritorialidades: projetos colaborativos, que se realizou no espaço urbano da cidade de Rio Branco, no Acre, trabalhava dentro da perspectiva de que o papel do artista era criar obras que pudessem provocar a reflexão e o pensamento, "arte comprometida com a criação de uma linguagem da percepção, que permite a flutuação da informação entre sistemas estranhos um ao outro, eliminando fronteiras para provocar novas associações e analogias". Ao levar as obras para a rua, a fronteira dos territórios institucionais (museus e galerias) é desconstruída, um público que usualmente não tem acesso a esses bens culturais passa a se relacionar com a obra, com seus significados e com a ação artística, o que seria essencial, pois, em sua opinião, é necessário que haja o encontro das duas subjetividades, a do público e a do artista.

Mas os novos territórios da arte não se expandiram apenas para as ruas, ganharam a rede, como atesta a "midiartista" Giselle Beiguelman, que desde 1996 faz trabalhos para a internet. Para ela, é essencial parar para refletir sobre uma estética de transmissão capaz de lidar com esse espectador que deve "agenciar leituras múltiplas e simultâneas, de conteúdos mediados por inúmeras variáveis sem controle". Seja nos computadores ou nos celulares, com telas grandes ou pequenas, é preciso observar as particularidades de recepção, como afirma a autora: "A mídia não conta. No tempo de práticas nômades, a interface é a mensagem".

Outra experiência interessante, ligada a uma mídia bem mais antiga, é a do atual gerente executivo de produção da TV Brasil, Walter Silveira. Depois de discorrer sobre o papel de uma televisão pública e de seu papel educativo, o autor registra dois projetos desenvolvidos por ele na TV Cultura, Arte \& Matemática e Contos da meia-noite, ambos trabalhando a questão da interdisciplinaridade. 0 trabalho dos VJs (video-jockeys), unindo imagem à música, é tema dos artigos de Lucas Bambozzi e Christine Mello. Nos seus trabalhos, as linguagens se misturam durante a performance "ao vivo", dependendo do retorno dado pelo público. "O improviso se impõe, acima de tudo, como compartilhamento de experiências, no ato de sua execução", escreve Bambozzi.

Ivone Mendes Richter vem propor outra forma de fazer uso das características da arte contemporânea para construir uma educação mais inclusiva, que respeite as individualidades e as características culturais de todos os alunos presentes na sala de aula. Através da multiplicidade de suportes e temas atuais (identidade, consumismo, intercâmbio entre culturas...), a arte contemporânea constitui-se como uma ótima ferramenta para discutir os problemas contemporâneos. Em seu trabalho, Richter buscou "detectar as origens étnicas presentes nos alunos dessa escola (escola Aracy Barreto Sacchis, na cidade de Santa Maria, no Rio Grande do Sul), para verificar se a estética do cotidiano dessas crianças sofria diferenciações por conta das diferentes origens étnicas". Nessa busca, foram en- 
contrados alguns "fazeres especiais", bordados, tecelagem, crochê, pintura... A partir dessa identificação, a autora foi em busca de artistas contemporâneos que trabalhassem alguns desses referenciais em seus trabalhos, como forma de valorizar as origens étnicas de seus alunos e propor a convivência entre as várias heranças presentes.

Em resumo, o livro Interterritorialidade - mídias, contextos e educação nos apresenta experiências, sejam elas com dança, com VJs, música ou artes plásticas, dentro de uma escola ou de um hospital, que mostram que a arte transita livremente por vários territórios e não pode ser colocada em categorias estanques. Propõe-nos que, ao invés de rejeitar e criticar a arte contemporânea e suas variadas formas híbridas, devemos aprender a usá-las ao nosso favor. Não sejamos apocalípticos. Para aprender a jogar, precisamos saber as regras. Como diz o crítico brasileiro Jorge Coli : "A fruição da arte não é imediata, espontânea, um dom, uma graça. Pressupõe um esforço diante da cultura. Para que possamos emocionar-nos, palpitar com um espetáculo de uma partida de futebol, é necessário conhecermos as regras desse jogo, do contrário tudo nos passará desapercebido, e seremos forçosamente indiferentes."

Mariana Oliveira (Jornalista na revista Continente - Brasil - www.revistacontinente.com.br ) 